\section{Estrategia de protección}

Desde la Delegación Provincial de Huelva se ha impulsado, en coordinación con la Dirección General de Bienes Culturales, la protección de un rico patrimonio etnológico vertebrador de un Paisaje Cultural fuertemente vectorizado por un elemento, el agua, que aquí lejos de ser un bien escaso, es, por contra, auténtico protagonista de un patrimonio cultural inserto y concurrente con un patrimonio natural conformador de un contexto físico fuertemente antropizado, el del Parque Natural de la Sierra de Aracena y Picos de Aroche.

Esta iniciativa de catalogación patrimonial se enmarca en una línea de trabajo que persigue la caracterización, inventario y protección efectiva del patrimonio cultural identificable en espacios naturales protegidos, postulando la vocación cultural de un patrimonio natural que es también patrimonio cultural en cuanto que ese medio físico ha sido antropizado para acoger, entre otras formas patrimoniales, una arquitectura hidráulica vernácula, que, como señala Fermín Seño Asencio, antropólogo redactor del expediente de catalogación, surge respondiendo a distintas soluciones tecnoculturales a las necesidades de captación, distribución y almacenamiento del agua, con una serie de materiales y técnicas constructivas propias e identificativas del lugar.

Las Jornadas sobre Paisajes Culturales celebradas en Ronda en julio de 2003, promovidas por el Instituto del Patrimonio Histórico Español, abordaron la cuestión de los llamados Paisajes del agua centrando el discurso en la huella paisajística trazada por las grandes infraestructuras marcadas por la ingeniería civil hidráulica y su labor vertebradora de ese territorio al que surte y del que se nutre. El ejemplo onubense que nos ocupa, centra su discurso, por contra, en una arquitectura erróneamente denominada menor, unas formas patrimoniales vernáculas que ilustran el tránsito entre el medio rural y el urbano de la mano de norias y molinos del rodezno, así como las lievas, acequias y albercas, que son germen del conjunto de cultivos irrigados y de los ruedos agrícolas periféricos a los núcleos de poblamiento serrano.

La centralidad de fuentes y lavaderos, enmarcados en el hecho urbano, en ocasiones sazonados de una pretetendida monumentalidad simbólica, ha servido de germen y catalizador del urbanismo de unos pueblos que en ocasiones han surgido en su derredor o desde trazados viarios que en ellos confluyen.

La estrategia de protección de este amplio conjunto patrimonial de orden etnológico pasa por la superposición de distintas categorías de inscripción en el Catálogo General del Patrimonio Histórico Andaluz (CGPHA).

Partiendo del expediente de inscripción genérica colectiva en el CGPHA de los bienes etnológicos de la cultura del agua de la Sierra de Aracena y Picos de Aroche, que pretende la identificación de los mismos como integrantes del Patrimonio Histórico Andaluz, la significación de alguna de estas formas patrimoniales ha permitido formular propuestas de inscripción específica con la categoría de lugar de interés etnológico de ámbitos como el conformado por la Fuente Redonda, la red de lievas y acequias, la alberca (conocida como La Laguna), y el conjunto de cultivos aterrazados irrigados del municipio de Cañaveral de León.

Las fiestas, los valores inmateriales que llegan de la mano de estas actividades etnológicas, culminan el puzzle patrimonial de este territorio. Son fiestas en las que el agua es el motivo relacional, o incluso central, y referente de una realidad patrimonial intangible fundada en su innegable simbolismo enraizado en la conformación de unos espacios para la sociabilidad. A lo largo de siglos el agua ha surcado este territorio y en su fluir ha ido marcando en lo más profundo de la cultura de sus pueblos un poso que permite erigirla en seña identitaria y en referente de un auténtico Paisaje Cultural que es en sí un paisaje de la cultura del agua.

Juan José Fonderilla Aparicio

Jefe de Servicios de Bienes Culturales

D.P. Cultura de Huelva

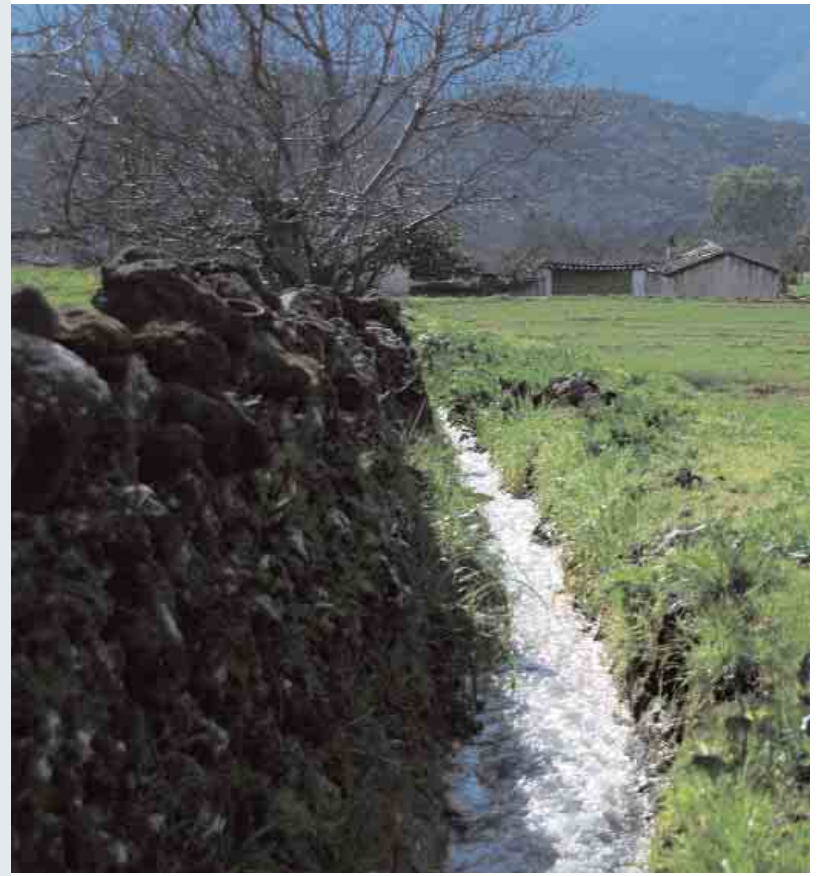

(1) Paisaje de Cañaveral de León / ANICETo DELGAdo, IAPH

y de sociabilidad hasta los simbólicos, confluían superpuestos en estos sistemas de abastecimiento de los que hoy podemos percibir sólo parte cuando observamos un lavadero restaurado, un pilar o un abrevadero.

Los paisajes del agua serranos nos hablan de usos que forman parte de la memoria de las gentes. Hubo un tiempo en el que el agua era la energía para la molienda del grano e incluso de la aceituna en los molinos, posteriormente convertidos en ruinas, algunos recuperados más recientemente y conocidos por su patrimonialización o restauración paras usos turísticos, otros olvidados y ocultos bajo la maleza del desuso. Entre los primeros destacamos las intervenciones sobre los molinos de Arroyomolinos de León, $y$, de entre los segundos, la aceña, hoy Mesón el Molino en Alájar, mientras que son numerosos los ejemplos de molinos hidraúlicos en ruinas repartidos por toda la sierra. Sean rui- 